\title{
Research on Fatigue For AIN - Cu Plate Jointed By DBC Method For Semi-Conductor Substrate
}

\author{
Qiao Ling Zhang ${ }^{1}$, Ting $\mathrm{Ai}^{1}$, Hao Kang ${ }^{1}$ \\ 1.Armored Forces Engineering institute of Army , ChangChun, China \\ zhangqiaoling10@163.com;65963974@qq.com ;29098545@qq.com
}

KeyWords: Residual stress, Stress intensity factor, thermal expansion coefficient

\begin{abstract}
A elastic-plastic analysis of AlN/Cu jointing plate was performed by FEM to study the residual stress produced in the jointing-cooling process. This residual stress due to the difference of thermal expansion coefficient between ceramics and metal was analyzed, considering the presence of initial defects in ceramics. A static fatigue life was estimated based on a stress intensity factor of the supper-posed stress of the residual stress and the bending stress in ceramics of $\mathrm{AlN} / \mathrm{Cu}$ jointing plate with the various thickness of $\mathrm{Al} 2 \mathrm{O} 3$ layer.
\end{abstract}

\section{INTRODUCTION}

According to the needs for the high power electric, the high integration and the modular structure of semi-conductor parts used for industrial machines, the AlN/Cu semi-conductor plate has been developed. This semi-conductor plate was jointed by ceramics and metal with DBC (direct bonding copper) method. The strength reliability of the AlN/Cu semi-conductor plate is afraid to be effected by the residual stress produced in the process of jointing-cooling. It becomes to be known that the residual stress is very important to estimate the long-period reliability of the AlN/Cu semi-conductor. In our paper, The static fatigue strength and the fracture mechanism of the AlN/Cu semi-conductor plate were discussed from the viewpoint of fracture mechanics, considering the presence of initial defects in ceramics, and a probabilistic fracture strength analysis was carried out on the basis of the fracture mechanics from one of innumerable initial microscopic defects. Also, the residual stress with various thickness of $\mathrm{Al} 2 \mathrm{O} 3$ layer was discussed and the estimation method of the static fatigue life for AlN/Cu semi-conductor plate was proposed..

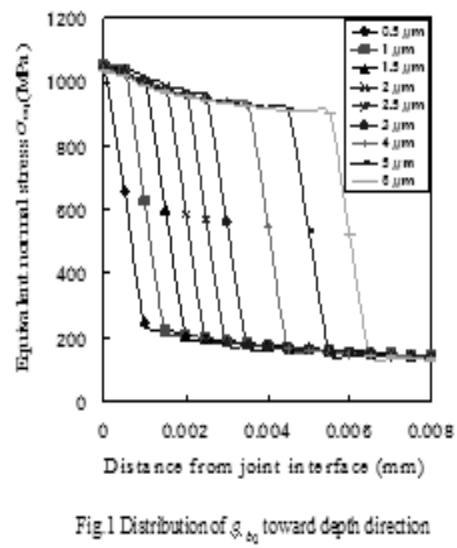

\section{TEST AND ANALYSIS METHOD}

A test specimens is the AlN/Cu semi-conductor plate jointed $\mathrm{Cu}$ plate $(\mathrm{B} 0.3 \times \mathrm{W} 8 \times \mathrm{L} 17)$ with $\mathrm{AlN}$ plate $(\mathrm{B} 0.8 \times \mathrm{W} 10 \times \mathrm{L} 40)$ at high temperature $\left(1065^{\circ} \mathrm{C}-1083{ }^{\circ} \mathrm{C}\right)$ in the oxygen concentration of 80 3900ppm with DBC method. Four-point bending tests were conducted for the test specimens at the cross-head speed of $0.04 \mathrm{~mm} / \mathrm{min}$, at room temperature in atmosphere. The elastic-plastic analysis was done about experimental rupture loads by the 4-point bending tests with FEM. The elasticplastic analysis was also done for the residual stress produced in the process of jointing-cooling. 
The thickness of $\mathrm{Al}_{2} \mathrm{O}_{3}$ layer on the surface of $\mathrm{AlN}$ was varied in order to study it's effect on the residual stress and the static fatigue strength.

\section{III.TEST AND ANAYSIS RESULT}

The fracture of ceramics occurs usually from one of innumerable initial defects under a multiaxial stress. The equivalent normal stress considering shear stress about initial defects under the multi-axial stress is given (1) by

$$
\sigma_{e q}=\sqrt{\sigma_{x}^{2}+\frac{4}{(2-v)^{2}} \tau_{x y}^{2}} . \quad \ldots \ldots \ldots \ldots \ldots . . .(1) \text { where, } \sigma_{\mathrm{x}}
$$

is a normal stress,$\tau_{\mathrm{xy}}$ is a shear stress, $\gamma$ is Poisson's ratio.

\section{A.The residual stress produced in the process of jointing -cooling}

The residual stress produced in the process of jointing-cooling indicates the maximum value at the second node from the jointing interface in the side of ceramics. The equivalent normal stress distribution toward depth direction is shown in Fig.1. Next, the stress intensity factor $\boldsymbol{K}_{\text {Ieq }}$ at the tip of a defect was analyzed against this equivalent normal stress $\sigma_{e q}$. Assuming that there is a surface semi-circle crack in the depth direction distribution of the residual stress containing the maximum value, the stress intensity factor $\boldsymbol{K}_{\boldsymbol{I e q}}$ is given by

$$
K_{\text {leq }}=2 \sqrt{\frac{\mathrm{a}}{\pi}} \int_{0}^{\mathrm{a}} \frac{\sigma_{e q}(y)}{\sqrt{\mathrm{a}^{2}-y^{2}}} d y
$$

where, a is the length of a surface semi-circle crack, $y$ is a distance toward depth direction.
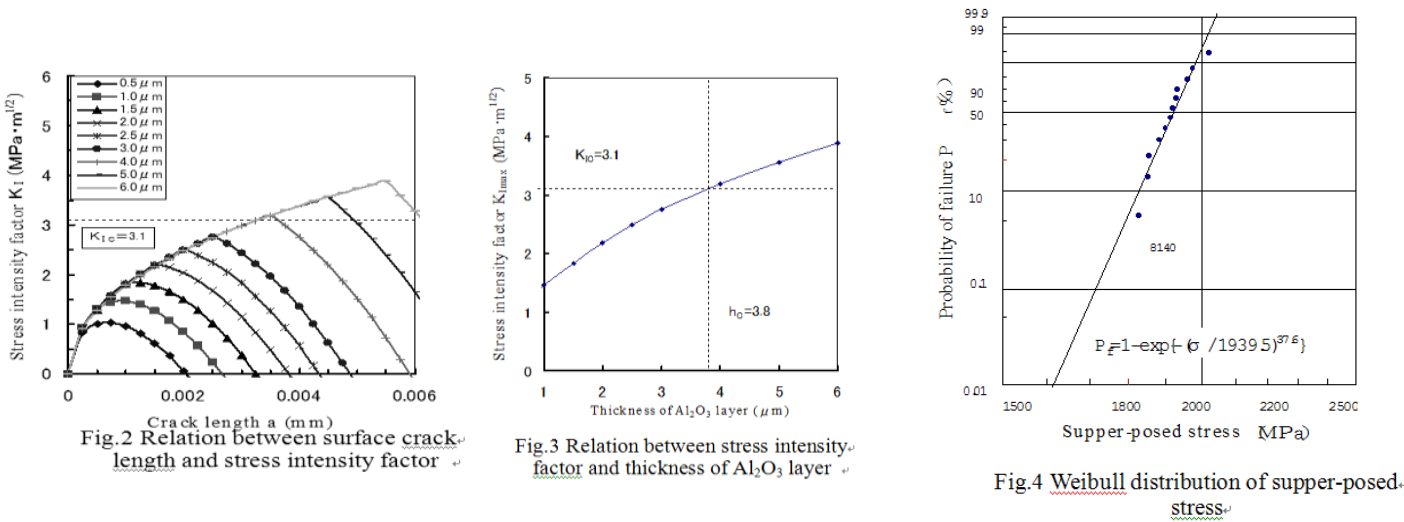

With every thickness of $\mathrm{Al}_{2} \mathrm{O}_{3}$ layer, the relation between the stress intensity factor $K_{\text {Ieq }}$ and the crack length $\boldsymbol{a}$ is shown in Fig.2. As seen in Fig.2, the $K_{\text {Ieq }}$ has the maximum value $\boldsymbol{K}_{\text {Imax }}$ in the case of a crack tip reaching the interface of $\mathrm{AlN}$ and $\mathrm{Al}_{2} \mathrm{O}_{3}$. On the other hand, the relation between the $\boldsymbol{K}_{\text {Imax }}$ and the $\mathrm{Al}_{2} \mathrm{O}_{3}$ layer thickness $\boldsymbol{h}$ is given in Fig.3. it is illustrated that the $K_{\text {Ieq }}$ is more than the fracture toughness $\boldsymbol{K}_{\boldsymbol{I} C}\left(3.1 \mathrm{MPam}^{1 / 2}\right)$ of $\mathrm{AlN}$ when the $\boldsymbol{h}$ is more than $3.8 \mu \mathrm{m}$. Therefore, if there is the defect penetrating through the $\mathrm{Al}_{2} \mathrm{O}_{3}$ layer more than $3.8 \mu \mathrm{m}$ in thickness, it can be estimated that the fracture will be caused by the crack growth toward AlN under the residual stress. Conversely, if $\mathrm{Al}_{2} \mathrm{O}_{3}$ layer is thinner than $3.8 \mu \mathrm{m}$, fracture wouldn't occur only due to the residual stress.

\section{B. the analysis of 4-point bending load}

For the purpose of estimating the true fracture strength $\tilde{\sigma}_{f(4 B)}$ of the AlN/Cu jointing specimens considering the residual stress, the equivalent supper-posed stress $\tilde{\sigma}_{e q}$ of both the residual stress $\sigma_{R}$ was analyzed. The fracture strength was discussed using this $\tilde{\sigma}_{e q}$. The probability of fracture $\boldsymbol{P}_{f}$ can be approximated well by two-parameter Weibull distribution as shown in Fig.4.

Weibull modulus $\boldsymbol{m}$ is 37.6 and scale parameter $\sigma_{0}$ is $1939.5 \mathrm{MPa}$. that a surface semi-circle crack with the length of $\boldsymbol{a}$ exists, the stress intensity factor $\boldsymbol{K}_{\mathbf{I}(\mathbf{4 B})}$ at this crack tip against is given (3) 


$$
K_{I(4 B)}=H \frac{\sigma_{b} \sqrt{\pi b}}{E(k)} F\left(\frac{b}{t}, \frac{b}{a}, \frac{a}{w}, \phi\right) \cdots
$$

where $\varphi$ is the angle of radius direction against $\mathrm{x}-\mathrm{z}$ plane direction. In the critical position of the semi-circle $\operatorname{crack}\left(\phi=0^{\circ}\right)$, the $\boldsymbol{K}_{\boldsymbol{I}(\boldsymbol{4 B})}$ have a maximum value. The relation between $\boldsymbol{K}_{\boldsymbol{I}(\boldsymbol{4 B})}\left(\phi=0^{\circ}\right)$ and $\boldsymbol{a}$ is shown in Fig.5.

Because the $\boldsymbol{K}_{\mathbf{I}(\mathbf{4 B})}$ in the position of $\left(\phi=0^{\circ}\right)$ is more than the $\boldsymbol{K}_{\boldsymbol{I}(\mathbf{4 B})}$ in the position of $\left(\phi=90^{\circ}\right)$, a surface penetrating crack can be formed at first. The $\boldsymbol{K}_{\boldsymbol{I}(\mathbf{4 B})}$ at the surface penetrating crack tip against 4-point bending stress is given

$$
K_{\mathrm{I}(4 B)}=f\left(\frac{\mathrm{a}}{W}\right) \frac{6 M}{B W^{2}} \sqrt{\mathrm{a}}
$$

where $\boldsymbol{a}$ is the surface penetrating crack depth. The critical condition judging fracture occur-

$$
\text { rence is given by } K_{\text {leq }}=\varphi \tilde{\sigma}_{e q} \sqrt{\pi c_{b}}
$$

where, $\varphi$ is a shape factor, $\boldsymbol{C}_{\boldsymbol{b}}$ is an initial surface defect size. If the $\boldsymbol{K}_{\boldsymbol{I} \boldsymbol{e}}$ is more than the $\boldsymbol{K}_{\boldsymbol{I C}}$ of AlN, fracture will occur. Based on Eq.(5), the $\boldsymbol{C}_{\boldsymbol{b}}$ can be estimated and expressed by

$$
c_{b}=\frac{1}{\pi}\left(K_{I C} / \varphi \sigma\right)^{2}
$$

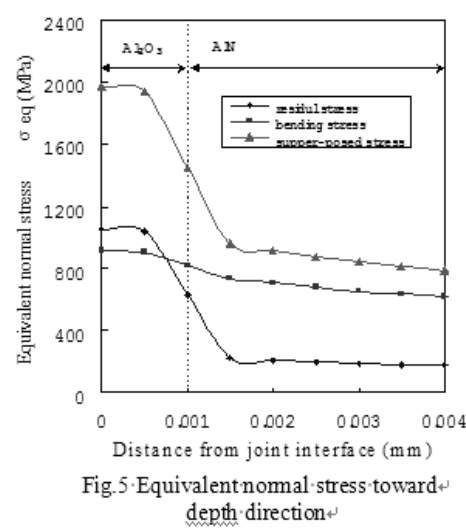

where, the shape factor $\varphi$ is 0.73 and $K_{I C}$ of $\mathrm{AlN}$ is $3.1 \mathrm{MPa} \cdot \mathrm{mm}^{1 / 2}$. As the result of estimation, the relation between the $\boldsymbol{C}_{\boldsymbol{b}}$ causing fracture and the $\tilde{\sigma}_{e q}$ is given as shown in Figs.5, But if there is a penetrating crack, the $\boldsymbol{K}_{I e q}$ of the penetrating crack with depth of $1.5 \mu \mathrm{m}$ is more than $\boldsymbol{K}_{I C}$ of AIN. By the way, as the $\mathrm{Al}_{2} \mathrm{O}_{3}$ layer is $1 \mu \mathrm{m}$ in thickness, the crack tip with depth of $1.5 \mu \mathrm{m}$ becomes to reach the inside of AlN ,and so rapid unstable fracture will occur. The $\tilde{\sigma}_{f(4 B)}$ is dominated by the unstable fracture juswhen the $\boldsymbol{K}_{\text {Ieq }}$ reaches the $\boldsymbol{K}_{\boldsymbol{I C}}$ of AlN. Therefore the strength of the semiconductor plate is dominated by the strength of AlN.

\section{THE STATIC FATIGUE PROPERTY OF SEMI-CONDUCTOR PLATE JOINTED BY DBC METHOD}

It is found from Fig.1 and Fig.3 that the $\sigma_{\text {Rmax }}$ in the $\mathrm{Al}_{2} \mathrm{O}_{3}$ layer is almost constant without regard to increase of the $\boldsymbol{h}$, but the $\boldsymbol{K}_{\text {Imax }}$ increases with increase of the $\boldsymbol{h}$. Therefore, from viewpoint of fracture mechanics, the static fatigue strength decreases with increase of the $\boldsymbol{h}$. As a expression to estimate the static fatigue life from the $\boldsymbol{h}$, Therefore the static fatigue life can be estimated by Eq.(7). 


$$
t_{f}=\frac{1}{\tilde{\sigma}_{e q}{ }^{n}}\left(\frac{K_{I C}}{\sqrt{\pi h}}\right)^{n}
$$

where $\boldsymbol{n}$ is a crack growth,The $\tilde{\sigma}_{e q}$ consists of the $\sigma_{R}$ and the $\sigma_{(4 B)}$. In the practical use of the semi-conductor plate, thermal stress $\sigma_{t h}$ may be considered instead of the $\sigma_{(4 B)}$. But, as $\sigma_{t h}$ is much more than $\sigma_{(4 B)}$, the thickness of $\mathrm{Al}_{2} \mathrm{O}_{3}$ layer was found to dominate greatly the static fatigue life.

\section{CONCLUSION}

The residual stress produced in the process of jointing-cooling was analyzed by FEM method. Taking the notice of the supper-posed stress of both residual stress, it was found that this supperposed stress is much more than by conventional same AlN materials. As for estimating the strength reliability of the semi-conductor plate, it was found to be very necessary to consider the residual stress. Also, the static fatigue properties with various thickness of $\mathrm{Al}_{2} \mathrm{O}_{3}$ layer was clarified through the concept of fracture mechanism and this static fatigue life could be quantitatively estimated based on the thickness of $\mathrm{Al}_{2} \mathrm{O}_{3}$ layer.

\section{REFERENCES}

[1] N.Okabe, Materials Science and Engineering,A143,11-19(1991).

[2] Matsui, M., Masuda, M., and Yamada, N. J. of Ceramics, Vol.25, No.2, 1990, pp.138-141.

[3] CHANG W R,Etsion I. An Elastic-plastic Model for the Contact of Rough Surfaces[J].Journal of Tribology(in Chinese),1987,(04):257-263.

[4] N.Okabe, and H.Hirata. CurrentJapanese Materials, Research A143,11-19(1991). Vol.14,ELSEVIER,( ,(1995),pp245

[5] Chuntian Yu Development and Prospect of metal matrix composites[J] forging,orging1994, (11)36-39 (in Chinese)

[6] Lingyun, Wang, Fusheng Pan Metal matrix composite solid/Research progress of preparation technology of liquid reaction [J], Chongqing University Journal,2004,24(11),151-156 (in Chinese)

[7] Okamura, H., "Beginning of Linear Fracture Mechanism”, Published by Baifukan, 76, pp. 216-219.

[8] Wang H·L,Th. Wagner,G. Eska,284-288. An aluminum heat switch made from cold-pressed CuAl composite[J].Physical Review B,2000.2024-2025. 